\title{
Subsurface Structure, Fault Zone Characteristics, and Stress State in Scientific Drill Holes of Taiwan Chelungpu Fault Drilling Project
}

\section{Introduction}

The 1999 Chi-Chi earthquake $\left(\mathrm{M}_{\mathrm{w}} 7.6\right)$ produced a $>90-\mathrm{km}$-long surface rupture zone along the north-south trending, west-vergent Chelungpu fault. The most striking feature of the coseismic displacement field is that areas of large surface displacement lie above the footwall ramp of the thrust and at the northern termination (up to $12 \mathrm{~m}$ ). An important question that needs to be addressed is what physical properties or dynamic processes within the fault zone cause large coseismic displacements in the northern segment. Hypotheses that have been proposed include 1) change of the fault-plane geometry (Yue et al., 2005); 2) static (long-term) physical properties such as intrinsic low coefficient of friction, high pore-pressure, and solutiontransport chemical processes; and 3) dynamic change of physical properties during slip. To address the above questions two holes (A and B) were drilled for the Taiwan Chelungpu Fault Drilling Project (TCDP) during 2004-2005 at Dakeng, west-central Taiwan, where large surface slip $(\sim 10 \mathrm{~m})$ was observed. Continuous coring and geophysical downhole logging in two holes 40 meters apart were completed from a depth of 500-2003 m (Hole A) and 950-1350 m (Hole B). Data from the drilled holes provide a unique opportunity to understand deformation mechanisms and physical properties of the Chelungpu fault where large slip occurred in the Chi-Chi earthquake.

\section{Subsurface Structure and Fault-Zone Characteristics}

Subsurface structure, stratigraphy, and corresponding log depth encountered in Hole A are shown in Fig. 1. Regional bed attitude above FZA1712, identified from cores and FMI/ FMS images in Hole A and from correlation of fault zones between Hole A and Hole B, is trending $\mathrm{N} 15^{\circ}$-E $21^{\circ}$, dipping $20^{\circ}-40^{\circ}\left(30^{\circ}\right.$ on average $)$ toward SE. Nonetheless, intervals of increasing (from $30^{\circ}$ to $75^{\circ}$ ) or decreasing (from $70^{\circ}$ to $20^{\circ}$ ) dip, as well as changes of dip azimuth, appear across fault zones. A gradual increase of bedding dip with depth starts from FZA1712, and a drastic change of dip from $20^{\circ}-40^{\circ}$ to $60^{\circ}-80^{\circ}$ occurs across FZA1855 where steep to overturned beds extend to the bottom hole.

A total of twelve fault zones identified in Hole A are located in the Plio-Pleistocene Cholan Formation, Pliocene Chinshui Shale, and Miocene Kueichulin Formation. Common fault rocks in the cores include intensely deformed fault core (clayey gouge) and adjacent highly fractured damage zones (fault breccia). The fault gouge is composed of ultra-finegrained clay minerals and massive to foliated fabrics; occasionally, thin layers of indurate black material appear within the gouge zone. A typical example is the Chelungpu fault zone, FZA1111 (Fig. 2). The fault is bedding-parallel consisting of fault breccia and fault gouge $1109 \mathrm{~m}$ to $1112 \mathrm{~m}$.

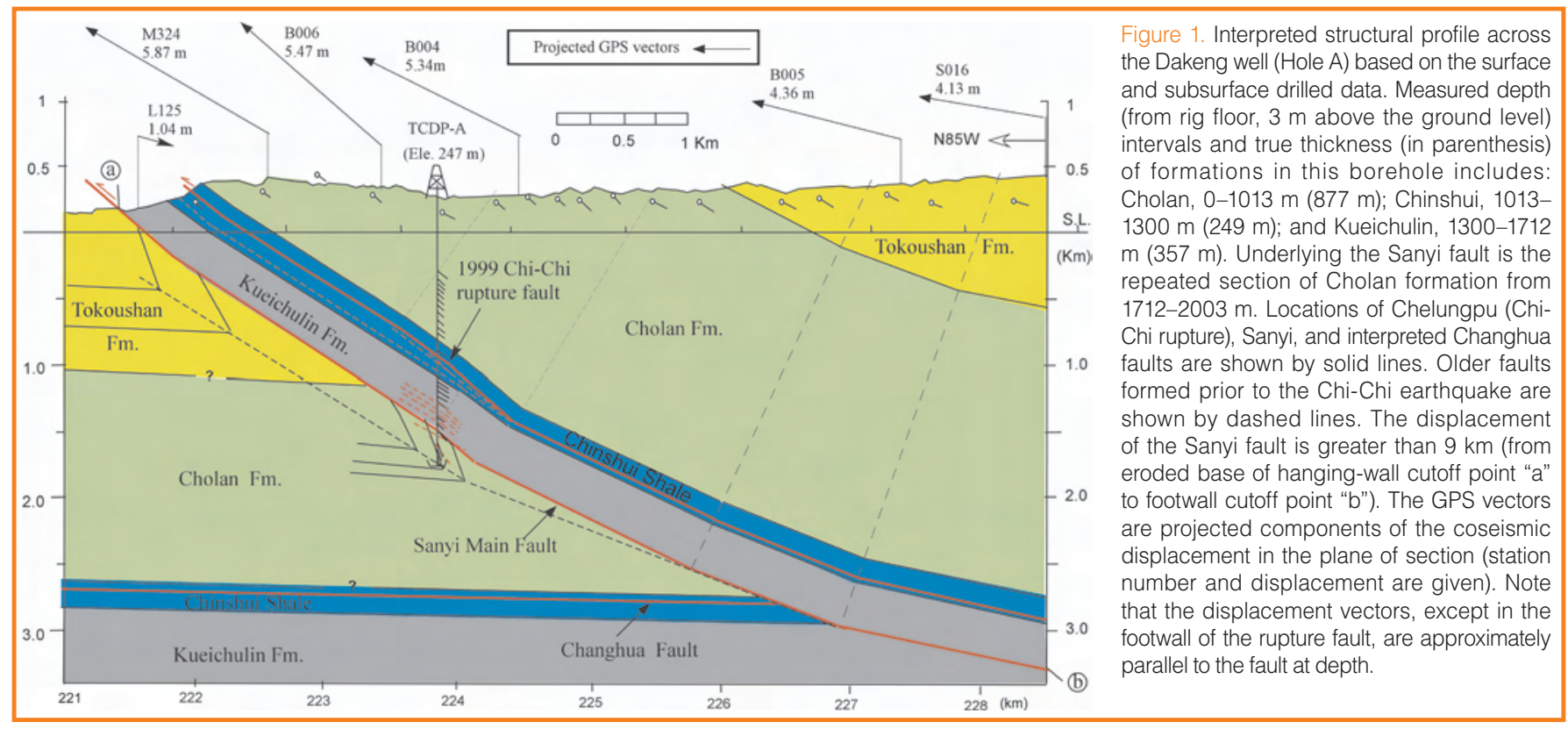




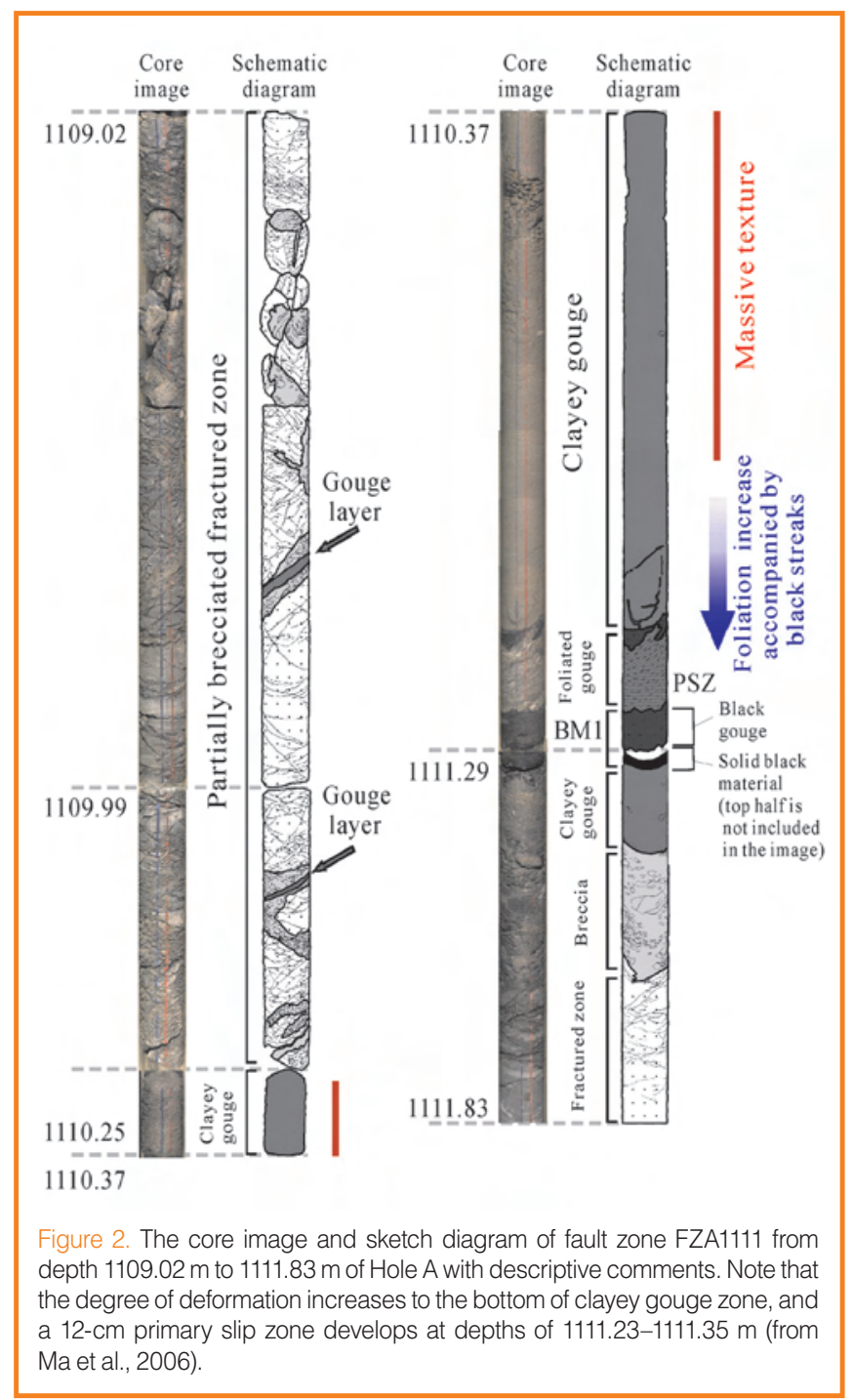

The degree of fracturing increases from the top of the damage zone towards the gouge zone in which the fabrics changed from massive to foliate between $1110.25 \mathrm{~m}$ and $1111.35 \mathrm{~m}$. The Chi-Chi major slip zone (MSZ, about $2 \mathrm{~cm}$ thick) is contained within the 12 -cm-thick primary slip zone (PSZ), which is located near the bottom of this broad gouge zone (Ma et al., 2006).

In spite of large surface displacements, no temperature anomaly was observed near FZA1111 due to circulation of mud immediately after the drilling. Nevertheless, Kano et al. (2006) reported a heat anomaly of $0.06^{\circ} \mathrm{C}$ during repeated temperature measurements 6 months after the completion of drilling.

\section{In situ Stress Measurements}

Leak-off test: A standard commercial procedure of openhole, extended leak-off tests was conducted in Hole B at depths between $940 \mathrm{~m}$ and $1350 \mathrm{~m}$ to determine in situ magnitudes of maximum $\left(\mathrm{S}_{\mathrm{H} \max }\right)$ and minimum $\left(\mathrm{S}_{\mathrm{H} \text { min }}\right)$ horizontal stresses. Successful leak-off tests have been done at four locations in Hole B-1279.6, 1179.0, 1085.0, and

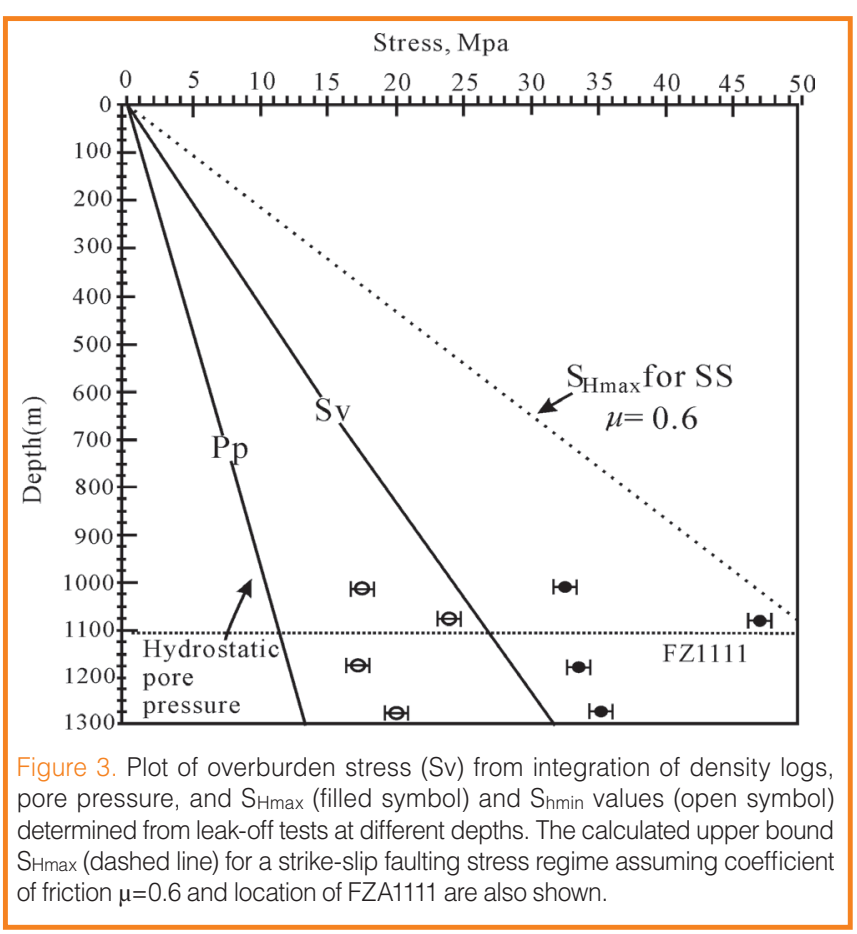

$1019.5 \mathrm{~m}$-with two above and two below the FZB1137 (equivalent to FZA1111). Given the depth of overburden, we can calculate the vertical stress from integration of density logs and compile with pore pressure and hydrofracturing data from various depths (Fig. 3). The measurements clearly indicate a strike-slip fault regime after the Chi-Chi earthquake in this area.

Wellbore failure: In situ stresses $\mathrm{S}_{\mathrm{Hmax}}$ determined from borehole breakouts and drilling-induced tensile fractures from Hole A and Hole B (Fig. 4) show that a significant change of $\mathrm{S}_{\mathrm{Hmax}}$ azimuth occurs across the depth of $1300 \mathrm{~m}$ (also a stratigraphic boundary between the Chihsui shale and the Kueichulin Formation). The $\mathrm{S}_{\mathrm{Hmax}}$ was oriented at $103^{\circ}-138^{\circ}$ with an average of $123^{\circ}$ in the section of $700-$ $1300 \mathrm{~m}$, as opposed to $137^{\circ}-164^{\circ}\left(154^{\circ}\right.$ on average) from $1300 \mathrm{~m}$ to $1700 \mathrm{~m}$. Borehole breakouts are relatively better developed in the Kueichulin Formation than in other places. This observation agrees with stronger anisotropy (stress magnitude) in the Kueichulin Formation, as shown by the shear wave anisotropy.

\section{Shear Seismic Wave Anisotropy}

Data from Dipole-Shear Sonic Imager (DSI ${ }^{\mathrm{TM}}$, Schlumberger) logs acquired over the interval of 508-1870 $\mathrm{m}$ in Hole $\mathrm{A}$ were used to assess shear wave velocity anisotropy. Analyses at these depths are shown by scatter plots and rose diagrams for nine discrete intervals of similar orientations of fast shear wave polarization (Fig. 5). A prominent NW-SE fast shear polarizing direction was generally observed except in a few depth zones, such as 738$770 \mathrm{~m}, 785-815 \mathrm{~m}$, and 1517-1547 m. In particular, a very consistent mean direction with small dispersion of $115^{\circ} \pm 1^{\circ}-$ $2^{\circ}$ (95\% confidence interval) appears in the strongly aniso- 
tropic Kueichulin Formation at 1300-1650 m. Relatively consistentfast shear polarization directions appear across FZA1111 (average $165^{\circ}$ between $1105 \mathrm{~m}$ and $1115 \mathrm{~m}$ ) compared to the interval of 1078-1190 m with trending in a much broader range of $130^{\circ}-170^{\circ}$. Thus, there is no observable systematic change of trend on fast shear polarization across the Chi-Chi slip zone. On the other hand, from the change of fast shear azimuth at depth $1000 \mathrm{~m}$ and contrasting dgree of anisotropy across the depth of $1300 \mathrm{~m}$, the perturbation of regional stresses may have occurred within the upper and lower boundaries of the Chinshui Shale as suggested from detailed study of borehole breakouts (Wu et al., 2007).

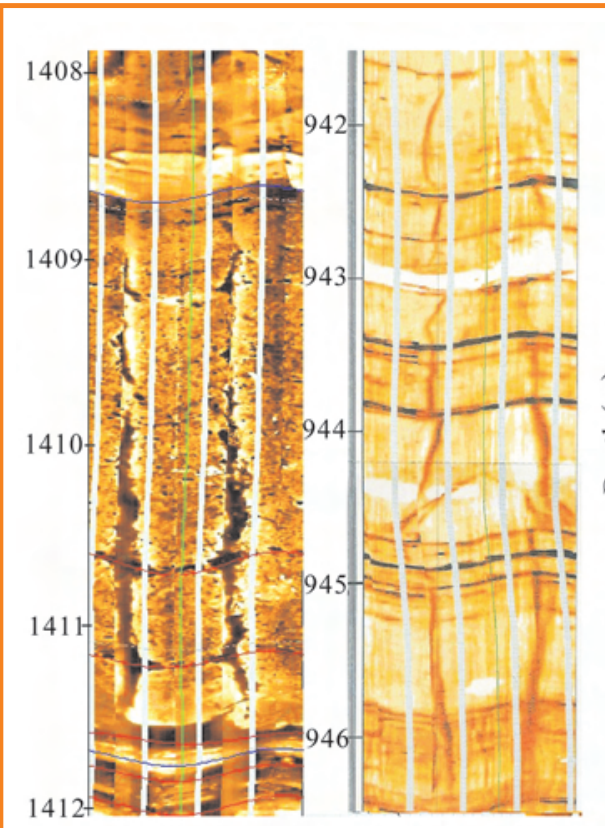

[A]

[B]
$\mathrm{S}_{\mathrm{Hmax}}$ stress direction (degree)

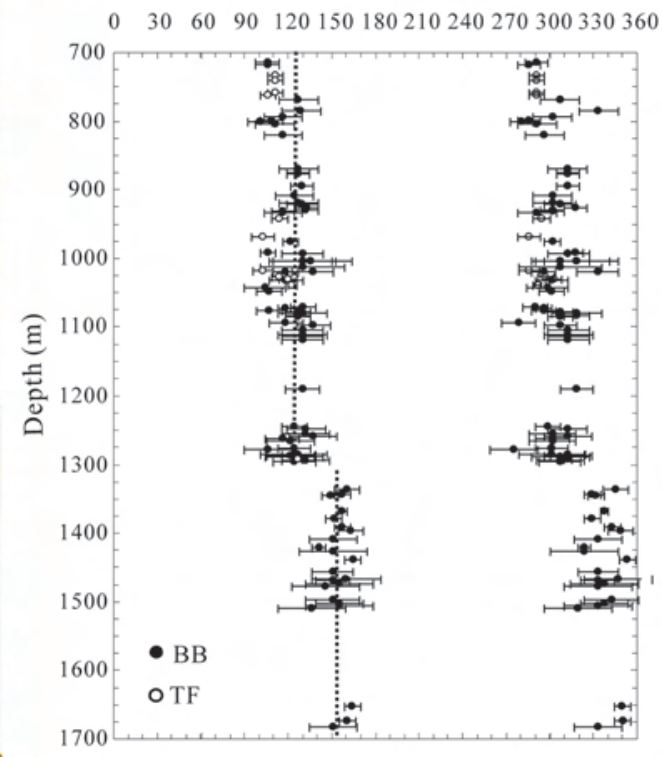

[C]

Figure 4. $[\mathrm{A}]$ Borehole breakouts as dark bands in opposite sides of the wellbore wall in FMl image logs of Hole $A$ between $1409 \mathrm{~m}$ and $1411 \mathrm{~m}$, and [B] drilling-induced tensile fractures in the Hole B at 941-947 m. [C] The plot of azimuth of Shmzx determined from breakouts (BO) and tensile fractures (TF) in the TCDP wells. Width of bar shows an opening angle of $\mathrm{BO}$ and TF with dark and open circles, respectively, as mid-point. Dotted lines are average of midpoints between sections of 700-1300 $\mathrm{m}$ and 1300-1700 $\mathrm{m}$.

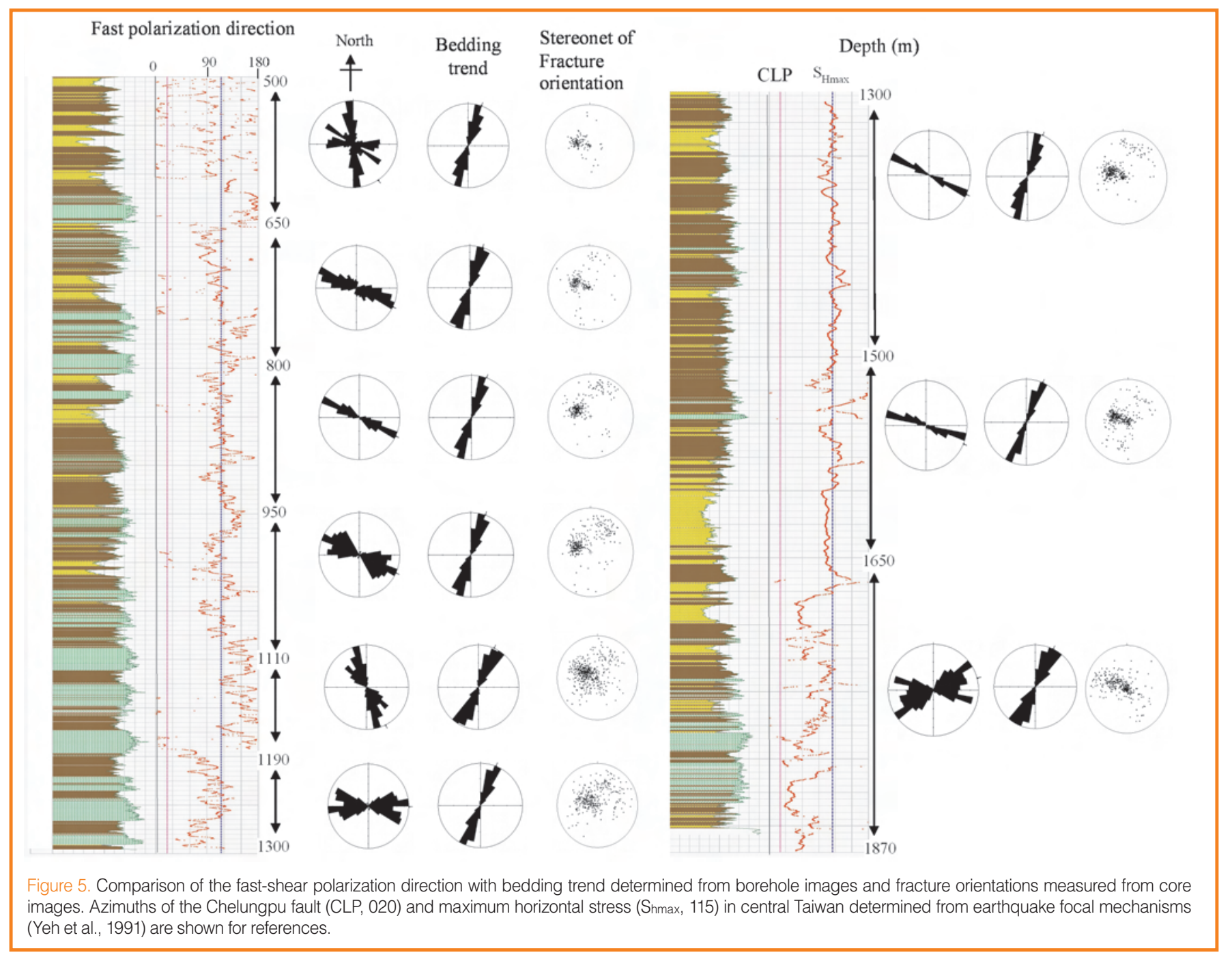




\section{Conclusions}

The major scientific goal of the TCDP boreholes is to understand the physical mechanism involved in the large displacement during the Chi-Chi earthquake. We have attempted to answer this and relevant questions through studies of subsurface structure, fault-zone fabrics, formation physical properties and in situ stress state. Consistent correlations among fault zone fabrics, physical properties and clay mineralogy enable us to identify the bedding-parallel fault zone at depth $1111 \mathrm{~m}$ in Hole A being the rupture fault. FZA1111 is a 1-m gouge zone including $12 \mathrm{~cm}$ of thick indurate black material, and is characterized by: 1) beddingparallel thrust fault with 30-degree dip; 2) the lowest resistivity; 3) low density, $\mathrm{V}_{\mathrm{p}}$ and $\mathrm{V}_{\mathrm{s}}$; 4) high $\mathrm{Vp} / \mathrm{V}_{\mathrm{s}}$ ratio and Poisson's ratio; 5) low energy and velocity anisotropy, and low permeability within the homogeneous gouge zone; 6) increasing gas $\left(\mathrm{CO}_{2}\right.$ and $\left.\mathrm{CH}_{4}\right)$ emissions, and 7) rich in smectite within the primary slip zone. The 2 -cm wide, ultra fine-grained and foliated clay gouge near the bottom of the FZ1111 is interpreted to be the slip zone during the Chi-Chi earthquake. Ancillary investigation of temperature signal around the FZ1111 suggests that the slip zone is low frictional strength with both low coefficient of friction and low shear stress.

In situ stresses at the drill site were inferred from, leak-off tests, borehole breakouts and drilling-induced tensile fractures from borehole FMS/FMI logs, and shear seismic wave anisotropy from DSI logs. The dominant fast shear wave polarization direction is in good agreement with regional maximum horizontal stress axis, particularly within the strongly anisotropic Kueichulin Formation. A drastic change in orientation of fast shear polarization across the Sanyi thrust fault at the depth of $1712 \mathrm{~m}$ reflects the change of stratigraphy, physical properties and structural geometry.

\section{Acknowledgements}

The TCDP is primarily funded by Taiwan National Science Council (NSC), R.O.C. under the contract of NSC91-2119-M008-030. We thank the International Continental Scientific Drilling Program (ICDP) for providing partial fund and technical consult. This research was supported by the Taiwan Earthquake Research Center (TEC) funded through NSC with grant number NSC94-2119-M-008-009. This article is a TEC contribution number 00021.

\section{References}

Kano, Y., Mori, J., Fujio, R., Ito, H., Yanagidani, T., Nakao, S., and Ma, K.-F., 2006. Heat signature on the Chelungpu fault associated with the 1999 Chi-Chi, Taiwan earthquake. Geophys. Res. Lett., 33:L14306, doi:10.1029/2006GL026733.

Ma, K.-F., Tanaka, H., Song, S.-R., Wang, C.-Y., Hung, J.-H., Tsai, Y.-B., Mori, J., Yeh, E.-C., Soh, W., Sone, H., Kuo, L.-W., and Wu,
H.-Y., 2006. Slip zone and energetics of a large earthquake from the Taiwan Chelungpu-fault Drilling Project. Nature, 444:473-476, doi:10.1038/nature05253.

Yeh, Y.-H., Barrier, E., Lin, C.-H., and Angelier, J., 1991. Stress tensor analysis in the Taiwan area from focal mechanisms of earthquake. Tectonophysics, 200:267-280, doi:10.1016/00401951(91)90019-O.

Yue, L.-F., Suppe, J., and Hung, J.-H., 2005. Structural geology of a classic thrust belt earthquake: the 1999 Chi-Chi earthquake Taiwan (Mw=7.6). J. Struct. Geol., 27:2058-2083.

Wu, H.-Y., Ma, K.-F., Zoback, M., Boness, N.., Ito, H., Hung, J.-H., 2007. Stress orientations of Taiwan Chelungpu-Fault Drilling Project (TCDP) hole-A as observed from geophysical logs. Geophys. Res. Lett., 34, L01303.

\section{Authors}

Jih-Hao Hung, Department of Earth Sciences and Institute of Geophysics, National Central University, No. 300, Jhongda Road, Johngli City, Taoyuan County, 32001, Taiwan (R.O.C.), e-mail:jhung@earth.ncu.edu.tw.

Kuo-Fong Ma, and Chien-Yin Wang, Department of Earth Sciences and Institute of Geophysics, National Central University, No. 300, Jhongda Road, Johngli City, Taoyuan County, 32001, Taiwan (R.O.C.).

Sheng-Rong Song, Department of Geosciences, National Taiwan University, No. 1, Sec. 4, Roosevelt Road, Taipei, 10617, Taiwan (R.O.C.).

Hisao Ito, Center for Deep Earth Exploration (CDEX), Japan Agency for Marine-Earth Science and Technology (JAMSTEC), 3173-25 Showa-machi, Kanazawa-ku, Yokohama, Kanagawa 236-0001, Japan.

Weiren Lin and En-Chao Yeh, Kochi Institute for Core Sample Research, Japan Agency for Marine-Earth Science and Technology (JAMSTEC), B200 Monobe, Nankoku, Kochi, 783-8502, Japan. 